\title{
Comment
}

\section{Psicologia da Educação: Essência da Educação Emancipatória}

\author{
Adriana Moura Maia ${ }^{1}$; Francisco Roberto Brito Cunha ${ }^{2}$
}

\begin{abstract}
Resumo: O presente artigo pretende discutir a importante e essencial relação entre psicologia e educação; sob as valiosas contribuições das correntes psicológicas Humanistas e Gestalt, para o ensino-aprendizagem; menciona a incindível e vital inter-relação aprendizagem e desenvolvimento apresenta metodologias inovadoras que busca norteiar o fazer pedagógico, objetivando mudanças de pensamentos e de atitudes no cotidiano escolar, para que a educação partilhada no referido ambiente propicie o educar para a vida como um todo. $\mathrm{O}$ aprender precisa despertar sempre o desejo de desvendar o conhecimento, através de ações que valorizem as competências e habilidades do educando ao ser estimulado para uma prática, na qual ele é protagonista da própria aprendizagem.
\end{abstract}

Palavras-chave: Psicologia da Educação; Humanista; Gestalt; Aprendizagem; Desenvolvimento; Inovação.

\section{Psychology of Education: Essence of Emancipatory Education}

\begin{abstract}
This article emphasizes the important and essential relationship between psychology and education; It addresses the valuable contributions of the psychological chains Humanists and Gestalt, for teaching and learning; mentions the inseparable and vital interrelationship learning and development and seeks mainly to provide innovative and effective methodologies to guide the pedagogical, aiming to change thoughts and attitudes in everyday school life, that shared education in that environment fosters the education for life as a whole. The learning must always awake the desire to unravel the knowledge, through actions that enhance the skills and educating the abilities to be stimulated to a practice in which he is the protagonist of their own learning.
\end{abstract}

Keywords: Educational Psychology; Humanist; Gestalt; Learning; Development; Innovation.

\section{Considerações Iniciais}

Diante de um novo cenário e de uma nova demanda, a necessidade de ações propulsoras de evolução, transformação, reestruturação, para a tão desejada educação significativa, eficaz e qualitativa. Assim, teorias, pensadores, valores, tripés, dentre outros, surgem e apresentam linhas de pensamentos e métodos, a fim de subsidiar e nortear a prática docente e o cotidiano escolar e educacional.

\footnotetext{
${ }^{1}$ Mestranda pela Anne Sullivan University. E-mail: adrianamoura.2007@ hotmail.com;

${ }^{2}$ Psicóloco Mestre pela UNIFOR, Professor do departamento de Educação da Universidade Regional do Cariri -URCA.

E-mail: frobertobrito@hotmail.com.
} 
Id on Line Revista Multidisciplinar e de Psicologia

Id on Line Multidisciplinary and Psycology Journal

Cada ser humano é um mundo desconhecido com inúmeras potencialidades, que precisa ser explorado, transformado, aperfeiçoado e valorizado para a concretização do objetivo principal do ato de educar: formar verdadeiros cidadãos. Partindo desse pressuposto, como concretizar a integração de novas experiências, que realizam e efetivam a eficiente aprendizagem no atual cenário da educação brasileira?

Ao longo do século XIX, a psicologia se consolidou como uma vertente filosófica, limitava-se a estudar o comportamento, as emoções e a percepção. O atomismo vigorava, já que se conhecia o todo através do conhecimento das partes.

Diante das advindas colaborações de algumas teorias, correntes e linhas psicológicas, pode-se afirmar que, cada uma com suas particularidades, contribuíram positivamente na história da educação brasileira, mas ressalto, no presente artigo, as teorias Humanista e Gestalt, pois apresentam ideias mais condizentes com meus pensamentos e ideais no que se refere a todo o processo educacional tão presente na minha prática pedagógica.

Não se pode afirmar que a Humanista tem uma significância maior que a Gestalt, e esta sobre aquela, pois se complementam, são interpostas e se tornam suportes importantes do educador quando a vivência escolar exige justificativas e metodologias inovadoras e satisfatórias, auxiliando-o a encontrar outros caminhos para efetivação da educação de qualidade. As escolas supracitadas como as demais sofreram muitas críticas apesar de suas valiosas contribuições, mas abriram novos horizontes e novos caminhos para a educação e para o surgimento de outros pensamentos psicológicos e científicos.

\section{A Psicologia da educação e a ótica da Humanista}

A psicologia humanista se destaca nos anos 60 e 70, na qual a questão central é o ser e a existência do todo, pois teve forte influência das filosofias existenciais e da fenomenologia, buscando, assim, dar uma nova contribuição à psicologia, apresentando uma reação às ideias psicológicas pré-existentes - o behaviorismo e a psicanálise.

O movimento humanista dá ênfase à integralidade entre a conduta do ser humano e o objeto e ao estudo de tudo que tenha relevância para a condição humana, pois, segundo a teoria, 
Id on Line Revista Multidisciplinar e de Psicologia

Id on Line Multidisciplinary and Psycology Journal

é somente mediante a perspectiva da totalidade, que a consciência é entendida. Seu valor reside na relação e na integração entre realidades e entre eu-mundo.

A teoria humanista tem como principais teóricos Abraham Maslow (1908-1970) e Carl Rogers (1902-1987), este teve o seu trabalho pautado no valor do indivíduo desde o início, com visões que advieram do tratamento de indivíduos emocionalmente perturbados; aquele considerado o pai espiritual do movimento humanista, acreditava na tendência inata que cada pessoa traz em si para se tornar autorrealizadora.

Maslow propôs a existência de níveis que deveriam obedecer a uma ordem de saciação, a serem satisfeitos através da hierarquia das necessidades: fisiologia, segurança, amor/relacionamento, estima e realização pessoal, este último, o nível mais alto da existência humana, onde a realização do potencial de cada indivíduo seria conquistada.

Rogers trabalhou com um conceito semelhante ao da autorrealização de Maslow: a tendência inata que cada ser humana tem de atualizar as capacidades e potencialidades do eu. Ele também defendeu a ideia de autoconceito percebida desde a infância, na medida em que se acumulam novas experiências, este conceito pode ser reforçado ou ser substituído por novos.

A teoria humanista tem como objetivo o não controle do comportamento, mas o crescimento pessoal do aprendiz. Visa à aprendizagem do todo que engloba a afetividade, a cognição e a psicomotricidade. Woolfolk (2000), diz que "ambientes de sala de aula que apoiam a autonomia do aluno estão associados com maior interesse, senso de auto competência e preferência por desafio".

De acordo com Rogers, o ser aprendente deve ser plenamente atuante, pois o objetivo é facilitar a aprendizagem, assim, o homem educado é o que aprendeu a aprender, o que aprendeu a adaptar-se a mudanças e o que sabe que a busca do conhecimento dá base para alguma segurança.

O educador deve ser um facilitador, um ser verdadeiro, autêntico, real com seus alunos, despojando-se do tradicional. Deve-se existir uma relação empática, onde haja a compreensão e a aceitação do outro com suas particularidades, ao aprender a ser aprendiz, independente e autêntico, ao ser compreendido e não julgado, pois a avaliação e a autoavaliação são elementos secundários. Segundo Rogers, só uma mudança muito grande na direção básica da educação, pode atender às necessidades da cultura de hoje. 
Id on Line Revista Multidisciplinar e de Psicologia

Id on Line Multidisciplinary and Psycology Journal

Além disso, Rogers também acredita na aprendizagem cooperativa bem planejada, pois propicia a disposição, o encorajamento e a aceitação das diferenças e das limitações dos colegas considerados de baixo rendimento e resulta em capacidade melhorada de ver o mundo e as pessoas.

Rogers descreve as aprendizagens e o conhecimento integrados com a vida ao considerar o aluno como um todo, sendo um ser consciente e autônomo com liberdade para decidir e com intencionalidade direcionada para um fim. Sua pedagogia é "centrada no aluno", portanto o que importa é a experiência e a responsabilidade do aluno no processo educacional, subsidiado no poder da pesquisa como método de aprendizagem.

\section{A Psicologia da educação e a ótica da Gestalt}

A teoria da Gestalt tem como ponto inicial e principal objeto a percepção, que se encontra entre os estímulos fornecidos pelo meio e a resposta do indivíduo. Nesta, a compreensão do comportamento humano está relacionado à percepção do que são e como são os importantes elementos do dia a dia.

Gestalt é um termo alemão de difícil tradução. O termo mais próximo em português seria forma ou configuração, que não é muito utilizado por não corresponder exatamente ao seu real significado em Psicologia. A Gestalt entende a psicologia como ciência do comportamento considerando os conteúdos conscientes e o comportamento em seus aspectos mais globais. Essa teoria pressupunha que a parte sempre se relacionava ao todo. Uma de suas formulações bastante conhecidas é a de que "o todo é diferente da soma das partes", ou seja, o resultado da simples adição não é percepção que temos de um todo.

Os três pesquisadores que marcaram essa corrente teórica foram Marx Wertheimer, Kurt Koffka e Wolfgang Köhler, os quais se embasaram nos estudos psicofísicos e relacionaram a forma e sua percepção. Defendiam que a experiência e a percepção são mais importantes que as respostas específicas no processo de aprendizagem. A experiência resulta da compreensão e percepção da aprendizagem, o que explica o porquê crianças, da mesma faixa etária, aprendem e apreendem de forma e ritmo diferentes, mesmo recebendo os mesmos estímulos e as mesmas condições. Segundo o psicólogo austríaco Christian von Ehrenfels: 
Há duas características da forma - as sensíveis, inerentes ao objeto, e a formais, que incluem as nossas impressões sobre a matéria, que se impregna de nossos ideais e de nossas visões de mundo. A união destas sensações gera a percepção. É muito importante nesta teoria a ideia de que o conjunto é mais que a soma dos seus elementos; assim deve-se imaginar que um terceiro fator é gerado nesta síntese. (1890)

Segundo a Gestalt, as estruturas intelectuais preexistem no todo ou em parte, desde o primeiro momento, sob a forma de organizações comuns à percepção e ao pensamento. A ideia central da mesma quanto à forma são interdependentes, os elementos jamais se constituem pela síntese, pois são percebidos em conjunto, não existem dados isolados, mas constituídos sempre em totalidades organizadas. Assim, a aprendizagem é uma reorganização do cognitivo, permitindo a compreensão de um problema e sua solução.

As interpretações de cada um tendem a ser individualizadas, porém as percepções por meio dos princípios da Gestalt são importantes ferramentas para a o nivelamento do processo de aprendizagem uma vez que os estímulos são criados pelo educador que já possui ideia das percepções mais comuns dentro do cenário criado. No processo de educação infantil pode ser aplicado da seguinte maneira: primeiramente se conceitua o todo, depois aos poucos o educador faz o desmembramento desse todo de modo que a criança conheça cada parte de um processo sem esquecer a sua finalidade. O estudo do corpo humano, por exemplo, é uma boa maneira de utilizar os conceitos da Gestalt, primeiro é informado sobre a função do corpo depois sobre as funções de cada órgão.

No processo de aprendizagem, recusa-se o exercício puramente mecânico. Os estímulos não agem de forma mecânica sobre um organismo passivo, pelo que o indivíduo participa ativamente no seu processo de aprendizagem. Segundo os gestaltistas a aprendizagem acontece através de insight e, portanto de transferências das aprendizagens para outros contextos, que se constitui numa compreensão súbita para solução de problemas.

A Gestalt apresenta-nos o conceito de percepção como o processo de descodificação dos estímulos que recebemos. O conhecimento é necessariamente adquirido através da percepção e, assim, cada indivíduo aprende devido às diferenças de percepção. O indivíduo e o objeto de estudo são protagonizadores da aprendizagem, surgindo, assim, uma inovadora visão de se fazer educação. 
Id on Line Revista Multidisciplinar e de Psicologia

Id on Line Multidisciplinary and Psycology Journal

Diante de novas ideias e ideais, a Gestalt sofreu muitas críticas, como todas as demais escolas de pensamento, pois os críticos da psicologia da mesma afirmavam que os processos perceptuais não eram vistos como científicos, que a teoria não apresentava conceitos básicos rigorosamente definidos por conta dos poucos dados quantitativos não passíveis a análise estatística. Porém os psicólogos da Gestalt ressaltaram que seus trabalhos apresentavam menos dados quantitativos porque presavam mais os dados qualitativos, pois pretendiam contribuir quanto à percepção, a aprendizagem, o pensamento, a personalidade, a psicologia social e a motivação. Muitos aspectos da psicologia cognitiva contemporânea devem sua origem à psicologia da Gestalt.

\section{A relação entre aprendizagem e desenvolvimento}

Com embasamento nas teorias supracitadas, pode-se afirmar que a aprendizagem é um processo constante e ininterrupto que depende das situações do dia a dia, enquanto o desenvolvimento é associado às resultantes transformações devido às experiências vivenciadas ao longo da vida. Ambos acontecem desde que nascemos, ou mesmo antes, e são processos complexos.

A aprendizagem e o desenvolvimento não dependem apenas da ação do mundo externo sobre o sujeito, mas também da ação do mesmo sobre o mundo, são trocas que constroem ideias particulares do sujeito sobre esta realidade. Ele é visto como ativo e não passivo no processo de aprendizagem.

É consenso entre os estudiosos que o desenvolvimento humano pode ser analisado a partir de, pelo menos, três aspectos: padrões universais, diferenças individuais e aspectos contextuais. Os aspectos contextuais, as representações internas e as relações interpessoais conferem individualidade ao sujeito.

Sabe-se que cada indivíduo possui suas particularidades, características que lhes são próprias, que o fazem comportar-se diferente em diversas situações: aprender de forma mais rápida ou mais lenta, ter atitude positiva ou negativa frente à vida. $\mathrm{O}$ ambiente em que o sujeito está inserido, seu contexto social, econômico e cultural e também suas relações na família, na 
Id on Line Revista Multidisciplinar e de Psicologia

Id on Line Multidisciplinary and Psycology Journal

escola e no trabalho, são aspectos contextuais extremamente relevantes a serem considerados na análise do processo de ensino-aprendizagem.

$\mathrm{Na}$ teoria piagetiana, as interações sociais contribuiriam mais para o desenvolvimento do juízo moral, das ideias sobre o que é certo e o que é errado, e mesmo o desenvolvimento deste juízo teria como pré-requisito o desenvolvimento cognitivo.

Nas teorias interacionistas que enfatizam o processo histórico-cultural de desenvolvimento humano, como a teoria de L. S. Vigotski e a de H. Wallon, a construção do psiquismo vai do interindividual para o intraindividual, isto é, das relações sociais para a relação do sujeito consigo mesmo.

Para estas teorias, o desenvolvimento não é promovido de todas as interações, mas daquelas que parte do conhecimento do aluno, das que o levam a pensar e a fazer além do que já pensa e faz. É necessário efetivar experiências e ações promotoras de aprendizagem, que não incidam sobre o sujeito unilateralmente, de fora para dentro. Destarte, educação é fundamental na promoção do desenvolvimento e da aprendizagem.

A aprendizagem escolar deve estar associada ao desenvolvimento humano em geral, já que impulsiona o intelecto, o afetivo e o social relacionados à apropriação das mediações culturais da sociedade.

\section{Considerações finais}

Conclui-se que, atualmente, diversas correntes e escolas são inerentes à educação brasileira, já que suas abordagens e teorias são subsídios e norteadores da prática pedagógica. Portanto, cabe ao educador ser um conhecedor das mesmas para um direcionamento mais eficaz para a aprendizagem significativa.

Apesar da existência de algumas discordâncias entre as teorias estudadas na psicologia, há uma consonância quanto à aprendizagem ao afirmarem que ela está relacionada com as experiências vividas durante o processo de desenvolvimento, como também, afirmam que a mesma ocorre em todo lugar e durante a vida toda, e não somente na escola, pois as teorias psicológicas foram tendo cada vez maior influência sobre a compreensão do processo de ensino e aprendizagem na escola. 
Id on Line Revista Multidisciplinar e de Psicoloqia

Id on Line Multidisciplinary and Psycology Journal

A aprendizagem e a compreensão são resultados da capacidade humana de adquirir, transformar e avaliar informações que obtemos da nossa experiência com o mundo. Assim, as atuais teorias procuram analisar o desenvolvimento numa perspectiva contextualistainteracionista, valorizando fatores como maturação biológica e aprendizagens realizadas nas relações sociais contextualizadas historicamente.

O desenvolvimento só é promovido mediante o impulsionamento das relações sociais, quando promovem os indivíduos para além do que já sabem, em lugar de trabalharem somente com o que já é conhecido, pois o todo é constituído pelas partes, mas as partes não são constituídas pelo todo.

Faz-se necessário o estudo aprofundado da relação entre Psicologia e Educação, já que é atual e relevante em face da grande influência da Psicologia no direcionamento das questões educacionais e no modo de encarar e buscar soluções para os problemas educacionais da modernidade.

A primordial proposta de intervenção sobre a atual situação seria a de capacitar os docentes para partir do que os alunos sabem e, aos poucos, "aculturá-los", com o objetivo de propiciar-lhes condições de ascensão social, levando em consideração desde fatores fisiológicos até psicológicos, passando por questões sociais e culturais.

É preciso trilhar caminhos desconhecidos, muitas vezes cheios de veredas, mas sempre com a convicção que é possível fazer diferente e de modo inovador, através de determinação e vontade de encontrar o meio para adentar neste universo enigmático e mágico que é o ser humano e, assim, concretizar ações significativas na prática pedagógica para a efetivação da verdadeira educação. Quem faz o diferencial é o educador, destarte, primordialmente, tem a capacidade de transformar.

\section{Referências}

KOFFKA, Kurt. Princípios de Psicologia da Gestalt. São Paulo: Cultrix, s.d.

PIAGET, Jean. Psicologia da inteligência. São Paulo: Forense, 1972.

ROGERS, Carl R. Liberdade de aprender em nossa década. Porto Alegre: Artes Médicas, 1985. 
Id on Line Revista Multidisciplinar e de Psicologia

Id on Line Multidisciplinary and Psycology Journal

ROGERS, Carl R. Tornar-se pessoa. 5. ed São Paulo: Martins Fontes, 2001.

VYGOTSKY, L.S. Pensamento e Linguagem. São Paulo: Martins Fontes, 1989.

WOOLFOLK, Anita E. Psicologia da educação. Porto Alegre: Artes Médicas, 2000.

\section{Como citar este artigo (Formato ABNT):}

MAIA, Adriana M.; CUNHA, Francisco R. B. Psicologia da Educação: Essência da Educação Emancipatória. Id on Line Revista Multidisciplinar e de Psicologia, Fevereiro de 2017, vol.11, n.34, p. 104-112. ISSN: 19811179 .

Recebido: 24.02.2017

Aceito: 27.02.2017 